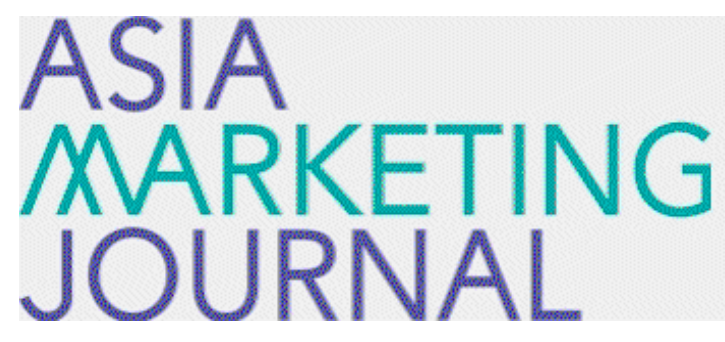

ASIA MARKETING JOURNAL

Volume 19 | Issue 2

Article 3

7-30-2017

\title{
Do We Always Hope to Become "Better" When We Experience Envy? Effects of Incidental Envy and Social Context on Self- Improvement Behavior
}

Y. Jin Youn

Kiwan Park

Follow this and additional works at: https://amj.kma.re.kr/journal

Part of the Marketing Commons

\section{Recommended Citation}

Youn, Y. Jin and Park, Kiwan (2017) "Do We Always Hope to Become "Better" When We Experience Envy? Effects of Incidental Envy and Social Context on Self-Improvement Behavior," Asia Marketing Journal: Vol. 19 : Iss. 2 , Article 3.

Available at: https://doi.org/10.15830/amj.2017.19.2.45

This Article is brought to you for free and open access by Asia Marketing Journal. It has been accepted for inclusion in Asia Marketing Journal by an authorized editor of Asia Marketing Journal. 


\title{
Do We Always Hope to Become "Better" When We Experience Envy? Effects of Incidental Envy and Social Context on Self-Improvement Behavior*
}

\author{
Y. Jin Youn** \\ Kiwan Park $^{* * *}$
}

\begin{abstract}
Incidental envy is known to motivate self-improvement behavior. This phenomenon occurs in part because feelings of inferiority guide subsequent behavior in a way to self-improve, after experiencing envy. However, no research has yet examined whether this tendency may be affected by social context: private versus public. Although extant literature suggests that envy generally leads to self-improvement, we demonstrate that this effect may be mitigated under public social contexts. Across two studies, we find that although incidental envy generally increases self-improvement behavior (e.g., effort exertion and charitable giving) in private social contexts, this tendency is attenuated under public social contexts. We conclude with a discussion of theoretical and practical implications of this finding.
\end{abstract}

Key words: envy, social context, self-improvement, emotion

\section{Introduction}

Imagine a woman experiencing envy while having a lunch with her colleagues. She learns that one of her friends has become engaged to be married, while the other has received a huge raise at work. After lunch, she returns to her office and learns that her company is soliciting donations for a certain cause. How will the lingering feelings of envy influence her decision to donate? Specifically, would the social context of whether the donation takes place either in public (e.g., having her name

\footnotetext{
* The authors gratefully acknowledge the financial support from the Institute of Management Research, Seoul National University

** SNU Business School Seoul National University (yj0925@snu.ac.kr), Corresponding Author

*** SNU Business School Seoul National University
} 
printed on the company newspaper) or in private (e.g., donating anonymously) influence her final decision? Envy is an emotion that is common to consumers (Belk 2011), which arises from upward comparisons to better-off others (Festinger 1954; Mussweiler, Ruter, and Epstude 2004). Thus, understanding the implications of incidental envy (i.e., envy that is experienced due to a prior, unrelated cause) on self-improvement behavior either in public or private social contexts can offer both theoretical advances and practical implications for marketers.

Prior research on envy predicts that this woman will be more likely to donate due to the motivational properties of envy (Van de Ven, Zeelenberg, and Pieters 2011a; Van de Ven, Zeelenberg, and Pieters 2011b), thereby overcoming her feelings of inferiority and improving self-evaluation (i.e., self-improvement). More broadly, self-improvement behavior of various forms increases after experiencing envy (Polman and Ruttan 2012; Van de Ven et al. 2011a; Van de Ven et al. 2011b). In other words, those who experience envy are more likely to engage in a wide array of behaviors to improve or enhance the self (Belk 2011). For example, incidental envy leads people to hold a high moral standard, and thus motivates them to become a more ethical person (Polman and Ruttan 2012). Similarly, incidental envy tends to boost individuals' performance on certain tasks, such as anagram tasks and remote associates tasks (Van de Ven et al. 2011b).

However, no research has yet demonstrated the role of social context in determining the influence of incidental envy on self-improvement behavior. As such, this research allows for the advancement of theory, given that extant research does not address whether or how incidental envy may influence consumers' propensity to engage in self-improvement behaviors across private and public social contexts. We propose that, while self-improvement behavior following envy generally increases when the behavior is performed in private circumstances (Polman and Ruttan 2012; Van de Van et al. 2011b), the proposed selfimprovement tendency is attenuated in the presence or recognition of others.

Then, why is self-improvement behavior mitigated when other people are watching or aware of one's behavior? Public social contexts have been shown to shift consumers' attention toward self-presentational concerns and away from maximizing their own self-interest, due to the potential for reputational consequences (Buss 1980; Froming, Walker, and Lopyan 1982). Here, public social contexts refer to contexts in which one's behavior or attitude is viewed, directly or indirectly, by others. For example, prior research has shown that when consumers' choices are publicly observable (versus private), they are more likely to switch from their original preferences (Ariely and Levav 2000) and incorporate more variety into their 
choices (Ratner and Kahn 2002) to make a favorable impression on others. In public social contexts, envious people may also shift their interest from self-improvement to other concerns related to self-presentation.

However, if the self-presentation motive is imperative, one may contend that self-improvement behaviors should be pursued more rather than avoided, in an attempt to make a good impression on others. In contrast, it is worth noting that public social contexts often decrease the confidence and performance of those who feel inferior, ironically due to impression management reasons (i.e., self-handicapping; Berglas and Jones 1978; Kolditz and Arkin 1982). This phenomenon often occurs when the situation is more diagnostic or demanding (e.g., a test that is important for the individual, a test that is observed or evaluated by others). Even experts exhibit decreased performance when there is an evaluative audience (Baumeister and Showers 1986). Because those who experience incidental envy undergo heightened feelings of inferiority, they may become more sensitive to the possibility that, in public contexts, self-improvement behavior may turn out to be unsuccessful. Furthermore, public situations in which people are generally aware of the relationship with and the presence of others make salient interdependent goals of fitting in with others, fulfilling social roles, and maintaining social connections. These interdependent goals may lead people to engage in a prevention focus rather than a promotion focus (Aaker and Lee 2001; Lee, Aaker, and Gardner 2000), thereby dampening self-improvement tendency further.

Based on the aforementioned research, we hypothesize that consumers who experience incidental envy will engage in self-improvement behavior only when social context is private. In contrast, we predict that such a tendency will attenuate in public social contexts. We test and confirm this prediction in two experiments that employ different conceptualizations of self-improvement behaviors drawn from prior research. To represent self-improvement behaviors, we use two tasks-time spent in unsolvable anagram tasks (experiment 1) and donation amount (experiment 2).

\section{Experiment 1: Envy, Social Context, and Effort Exertion}

The objective of experiment 1 was to provide a test for the proposed effect of social context on self-improvement behavior following the experience of envy. As self-improvement behavior, we employed a standard method of effort exertion on a performance task. Specifically, we used time spent on the unsolvable anagram as our dependent measure (e.g., Shah, Higgins, and Friedman 1998). 


\subsection{Method}

Three hundred and eleven participants from Amazon's Mechanical Turk $\left(M_{\text {age }}=24.96, S D\right.$ $=9.19 ; 64 \%$ male) were randomly assigned to one of four conditions in a 2 (social context: public vs. private) $\times 2$ (emotion: envy vs. neutral) between-participants design. All participants were informed that they would be completing a series of unrelated tasks. The first task was entitled "Past Experience Recall," and participants were instructed to visualize and recall either a prior experience when they envied another person (envy condition) or their activities of yesterday (neutral condition), depending on their experimental assignment (adapted from Malatesta and Izard 1984; Appendix A for stimuli).

In the second task, all participants were provided with a series of anagrams, described as "word jumbles" (Goldsmith and Dhar 2013). They were instructed that this task required them to rearrange letter strings (e.g., etkbas) into English language words (e.g., basket). Four of the five anagrams that participants received were solvable, whereas the final anagram had no solution. This final anagram was included since persistence on impossible tasks has been commonly employed as a measure of effort in prior work (Shah et al. 1998).

For those in the public condition, participants were told that their performance would be shared amongst other researchers (i.e., "your data will be analyzed by a team of researchers at a large Midwestern University and ultimately reviewed by researchers at several different universities"). In contrast, in the private condition, no information was provided about whether anyone would review the participants' performance. Time spent on the unsolvable anagram served as the dependent measure.

\subsection{Results and Discussion}

We predicted that self-improvement behavior (here, effort exertion) following incidental envy would be mitigated in public, as compared to private, social contexts. This was tested using a 2 (social context) $\times 2$ (emotion) ANOVA on time spent on the unsolvable anagram (in seconds). Results revealed a significant interaction between social context and emotion $(F(1,307)=7.51, p=.006$; Figure 1). Replicating the effects observed in prior research, when the social context was private, those experiencing incidental envy $(M=70.48, S D=80.85)$ exerted (marginally) more effort than those in the neutral-emotion condition $(M=47.38, S D=54.65 ; F(1,307)$ $=3.51, p=.062)$. More importantly, however, the public context attenuated this effect; participants experiencing incidental envy ( $M=$ 51.58, $S D=50.46$ ) exerted less effort than those in the neutral-emotion condition $(M=$ 76.49, $S D=101.15 ; F(1,307)=4.01, p=$ 
〈Figure 1> Time spent on unsolvable anagram as a function of social context and envy (experiment 1).

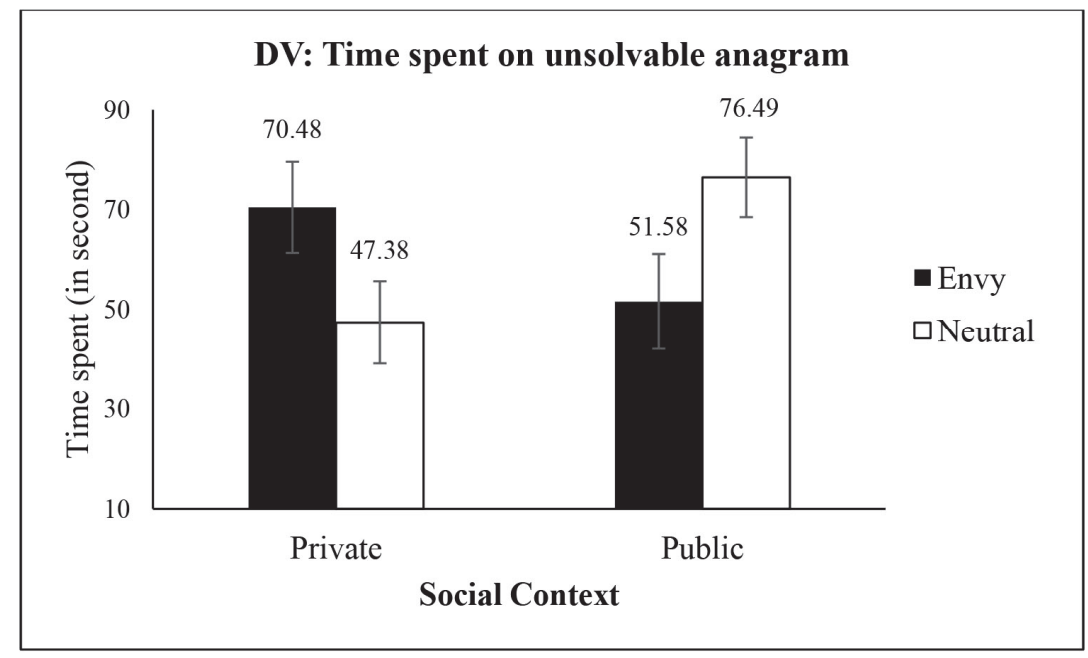

.046). No significant main effects emerged in this analysis $\left(F_{\mathrm{S}} \leq .34, \mathrm{ps} \geq .56\right)$.

Thus, experiment 1 provided evidence for the moderating role of social context on the influence of envy on self-improvement behavior. One limitation of this experiment was that those in the private condition did not receive any substantial information regarding who would be viewing their performance data. Therefore, participants in the private condition might have had varying assumptions regarding whether or not their performance would be evaluated by others. The next experiment addressed this limitation by introducing a less ambiguous manipulation of social context, in addition to replicating the observed interaction in a different self-improvement behaviordonation.

\section{Experiment 2: Envy, Social Context, and Charitable Giving}

The goal of experiment 2 was two-fold. First, experiment 2 tested for convergence with the prior results by utilizing a different manipulation of incidental envy. Second, experiment 2 employed charitable giving as a self-improvement behavior. Prior research suggests that prosocial behavior can serve a self-improvement function and positively improves one's well-being (Houle, Sagarin, and Kaplan 2005; Weinstein and Ryan 2010).

\subsection{Method}

One hundred and thirty-three students $\left(M_{\text {age }}\right.$ $=23.15, S D=2.75 ; 37 \%$ male) from a large 
Midwestern University in the US were randomly assigned to one of the eight conditions in a 2 (social context: public vs. private) $\times 2$ (emotion: envy vs. neutral) $\times 2$ (gender: male vs. female) between-participants design. All participants were informed that they would be completing a series of unrelated tasks. Next, participants indicated their gender and were then randomly assigned to one of the two emotion-induction conditions.

For emotion induction, participants were told that they would be evaluating a recent online interview given by another student at their university. Because prior research has shown that envy is most frequently experienced as a result of comparisons to same-sex others (Hill and Buss 2008; Tesser, Millar, and Moore 1988), males (females) were assigned to read an article about a fictional male (female) student. The contents of the interview were adapted from Hill and colleagues (2011) and modified only to reflect the students' own university. Except for the name, picture, and all gendered pronouns, the interview contents remained consistent across genders. In the envy condition, participants read about a fictional student who possessed a great deal of wealth and material possessions, whereas in the neutral-emotion condition, participants read about a fictional student of relatively average financial means (Appendix B for stimuli).

To validate the effectiveness of the manipulation, a pre-test $(n=51)$ was conducted in which participants from the same population (i.e., university students attending the same school) as the main study were randomly assigned to read the interview from either of the two emotion conditions. The gender of the interviewee was matched with that of the participant. A 2 (emotion) $\times 2$ (gender) ANOVA revealed that those in the envy condition felt significantly more envy $(M=3.92, S D=2.32)$ toward the interviewed student than those in the neutralemotion condition $(M=2.21, S D=1.01$; $F(1,47)=14.17, p<.001)$. No other effects were significant.

After reading the interview scenarios, all participants moved on to what was presented ostensibly as unrelated charitable giving. In this task, they were asked to imagine that they had recently started a new job at a firm where charitable donations were encouraged. In the public condition, participants were told that each donor's name and donation amount would be published in the "Donation Page" section of the company's newspaper. In the private condition, they were told that all donations were entirely anonymous. All participants were asked how much money they would commit to donating to a charity of their choice, on a scale of $\$ 0-\$ 100$. The donation amount served as the dependent variable.

\subsection{Results and Discussion}

A 2 (social context $) \times 2($ emotion $) \times 2$ 
〈Figure 2〉 Donation amount as a function of social context and envy (experiment 2).

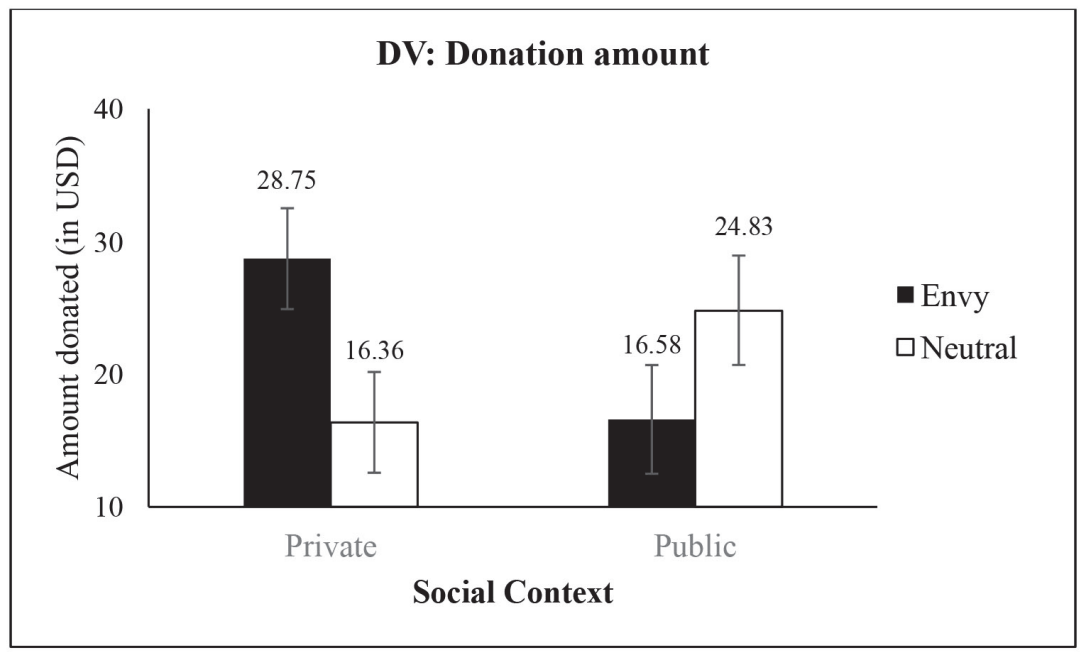

(gender) ANOVA on donation amount revealed a significant interaction between social context and emotion $(F(1,125)=6.55, p=.012$; Figure 2). As in experiment 1 , when the social context was private, participants experiencing incidental envy $(M=28.75, S D=29.16)$ donated significantly more than those in the neutral-emotion condition $(M=16.36, S D=$ 19.83; $F(1,125)=4.58, p=.034)$. More importantly, however, when the social context was public, this effect was mitigated. In the public context, participants who experienced incidental envy $(M=16.58, S D=16.03)$ directionally donated less money than those in the neutral-emotion condition $(M=24.83, S D=$ 23.14), but the difference was not significant $(F(1,125)=2.28, p=.134)$. No other significant effects emerged in this analysis $\left(F_{\mathrm{S}} \leq 2.08, p \mathrm{~s} \geq .152\right)$.

\section{General Discussion}

In this research, we hypothesize that consumers who experience incidental envy are motivated to engage in self-improvement behaviors in private social contexts, but instead suppress such behaviors in public social contexts. We test this prediction in two experiments by manipulating both social context (public versus private) and emotion (envy versus neutral). We find robust support for the predicted interaction between these factors, which was validated on two different dependent measures of self-improvement behaviors suggested by prior research. By doing so, to the best of our knowledge, this work is the first to demonstrate that social context works as an important moderator to the previously-acknowledged positive 
effect of incidental envy on self-improvement.

The present research offers important theoretical contributions to the literature on incidental envy and social context. First, although envy is a common emotion that significantly affects various consumer behaviors (Belk 2011), the influence of envy on behaviors unrelated to the envy-inducing target has been largely underexplored. Prior research on envy has primarily focused on how this emotion influences people's perception and behavior toward the target who evoked the emotion (Hill, DelPriore, and Vaughan 2011; Van de Ven et al. 2011a). Our findings suggest that incidental envy influences subsequent unrelated self-improvement behaviors by demonstrating that incidental envy affects one's tendency to exert effort and to engage in charitable giving. As such, the present research adds to the scant literature of incidental envy by providing evidence on how and when incidental envy leads to self-improvement behaviors.

Second, although social context is a critical factor that influences a variety of consumer behaviors (Froming et al. 1982; Ratner and Kahn 2002), the relationship between social context and incidental envy has, to the best of our knowledge, never been investigated. Prior research suggests that public social contexts may increase self-improvement behaviors due to the heightened self-presentational concerns. This is why people are more likely to engage in self-improvement behavior in public contexts to increase the reputation of self to others (Gneezy et al. 2012). The current research offers substantial evidence that when people experience incidental envy, this is not the case. We demonstrate that consumers' self-improvement behavior following the experience of incidental envy may be hampered in a public social context. This finding not only adds to the literature of envy by suggesting a meaningful moderator in examining the influence of incidental envy on self-improvement behaviors, but also to that of social context by demonstrating how the presence of others alters consumers' behavior under the influence of envy.

Finally, the current paper investigates prosocial behavior as a proxy to measure self-improvement. Specifically, we test whether envy and social context influences consumers' tendency for charitable giving. In doing so, we add to the vast literature of why and when people engage in prosocial behavior (Bartlett and DeSteno 2006; Bénabou and Tirole 2006; Clary and Snyder 1991; Weinstein and Ryan 2010). Envy proves to be one of the factors that are critical to determining engagement in prosocial behavior.

Although our results demonstrate that the influence of incidental envy on self-improvement behavior is moderated by social context, there are several limitations. First, given that the focal interest in the current research was on investigating whether social context could influence self-improvement behavior after the experience of incidental envy, we did not 
distinguish between different types of envy. Future research may broaden this inquiry by examining whether the type of envy consumers experience may change how the interplay between envy and social context affects decisionmaking. For example, prior research has demonstrated that envy can be either malicious or benign (Van de Ven, Zeelenberg, and Pieters 2009; Van de Ven et al. 2011a; Van de Ven et al. 2011b). By activating either of the two types of envy, future research could test whether these different types have distinct carry-over effects on unrelated behaviors, potentially moderated as a function of social context. Then, researchers may be able to form a more nuanced framework for understanding how envy interacts with social context to determine subsequent self-improvement behavior.

Second, other behaviors that may be influenced by incidental envy need to be explored. Envy can evoke multiple motivations and desires that are related to the self and others. As such, incidental envy might influence our behavior in competition, cooperation, or relationships. Hence, it will be fruitful to explore whether incidental envy and social context affect behaviors in unrelated domains besides self-improvement.

Finally, although we provided substantial evidence on the relationship between incidental envy and social context on self-improvement behavior, a direct test on the underlying mechanism was not conducted. We argue that the demonstrated phenomenon emerged due to several factors related to public social context (e.g., self-presentational concerns, impression management, and prevention focus). Thus, empirical evidence on the specific process that drives the proposed effect is an area that calls for further investigation. Future studies should be conducted to test specific aspects of public social contexts that motivate people to engage less in self-improvement behavior when experiencing incidental envy.

The current findings suggest several important practical implications for marketers. For example, many charitable organizations collect donations in public (e.g., collection boxes) and private (e.g., online) contexts. Because envy is prevalent in everyday life, understanding how envy influences consumers' tendency toward donations depending on social context may be important for their marketing strategy. Our findings suggest that incidental cues that may activate envy (e.g., the presence of indulgent products; Savary, Goldsmith, and Dhar 2015) may not be beneficial in public collection locations; however, such cues should increase private donations.

These findings also offer suggestions for managers seeking to promote self- improvement behaviors in a public workplace. They should be cautious in employing any practices that might activate incidental envy (e.g., performance rankings), as doing so may have unintended negative consequences on exerting efforts. Eliciting feelings of inferiority through social comparison may boost one's motivation to 
self-improve internally. However, the same practice of generating envy could attenuate self-improvement behavior, particularly in public social contexts. Our results offer a useful maxim for managers and marketers: envy is good internally, but may be bad externally.

〈Received June 16. 2017〉 〈Accepted August 3. 2017〉

\section{References}

Aaker, Jennifer L. and Angela Y. Lee (2001), " "I" Seek Pleasures and "We" Avoid Pains: The Role of Self-Regulatory Goals in Information Processing and Persuasion," Journal of Consumer Research, 28(1), 3349. doi: 10.1086/321946

Ariely, Dan and Jonathan Levav (2000), "Sequential Choice in Group Settings: Taking the Road Less Traveled and Less Enjoyed," Journal of Consumer Research, 27(3), 279-90. doi: 10.1086/317585

Bartlett, Monica Y. and David DeSteno (2006), "Gratitude and Prosocial Behavior: Helping When It Costs You," Psychological Science, 17(4), 319-25. doi: 10.1111/j.1467-9280. 2006.01705.x

Baumeister, Roy F. and Carolin J. Showers (1986), "A Review of Paradoxical Performance Effects: Choking Under Pressure in Sports and Mental Tests," European Journal of
Social Psychology, 16(4), 361-83. doi: 10. 1002/ejsp.2420160405

Belk, Russell (2011), "Benign Envy," AMS Review, 1(3-4), 117-34. doi: 10.1007/ s13162-011-0018-x

Bénabou, Roland and Jean Tirole (2006), "Incentives and Prosocial Behavior," American Economic Review," 96 (5), 1652-678. doi: 10.1257/000282806779396283

Berglas, Steven and Edward E. Jones (1978), "Drug Choice as a Self-Handicapping Strategy in Response to Noncontingent Success," Journal of Personality and Social Psychology, 36(4), 405-17. doi: 10.1037/ 0022-3514.36.4.405

Buss, Arnold H. (1980), Self-consciousness and Social Anxiety. San Francisco, CA: Freeman.

Clary, E. Gil and Mark Snyder (1991), “A Functional Analysis of Altruism and Prosocial Behavior: The Case of Volunteerism." in Prosocial Behavior, Margaret S. Clark, ed. Thousand Oaks, CA: Sage, 119-48.

Festinger, Leon (1954), “A Theory of Social Comparison Processes," Human Relations, 7, 117-40. doi: 10.1177/001872675400700202 Froming, William J., G. Rex Walker, and Kevin J. Lopyan (1982), "Public and Private Self-Awareness: When Personal Attitudes Conflict with Societal Expectations," Journal of Experimental Social Psychology, 18, 476-87. doi: 10.1016/0022-1031(82)90067-1 Goldsmith, Kelly and Ravi Dhar (2013), 
"Negativity Bias and Task Motivation: Testing the Effectiveness of Positively Versus Negatively Framed Incentives," Journal of Experimental Psychology, 9(4), 358-66. doi: 10.1037/a0034415.

Gneezy, Ayelet, Uri Gneezy, Gerhard Riener, and Leif D. Nelson (2012), "Pay-WhatYou-Want, Identity, and Self-Signaling in Markets," Proceedings of the National Academy of Sciences, 109(19), 7236-240.

Hill, Sarah. E and David M. Buss (2008), "The Evolutionary Psychology of Envy," in Envy: Theory and Research, Richard. H. Smith, ed. New York, NY: Oxford, 60-70.

Hill, Sarah E., Danielle J. DelPriore, and Phillip W. Vaughan (2011), "The Cognitive Consequences of Envy: Attention, Memory, and Self-Regulatory Depletion," Journal of Personality and Social Psychology, 101(4), 653-66. doi: 10.1037/a0023904

Houle, Barbara J., Brad J. Sagarin, and Martin F. Kaplan (2005), “A Functional Approach to Volunteerism: Do Volunteer Motives Predict Task Preference?" Basic and Applied Social Psychology, 27(4), 337-44. doi: 10.1207/s15324834basp2704_6

Jones, Edward E. and Steven Berglas (1978), "Control of Attributions About the Self Through Self-Handicapping Strategies: The Appeal of Alcohol and the Role of Underachievement," Personality and Social Psychology Bulletin, 4(2), 200-06. doi:
10.1177/014616727800400205

Kolditz, Thomas A. and Robert M. Arkin (1982), "An Impression Management Interpretation of the Self-Handicapping Strategy," Journal of Personality and Social Psychology, 43 (3), 492-502. doi: 10.1037/0022-3514.43.3.492 Lee, Angela Y., Jennifer L. Aaker, and Wendi L. Gardner (2000), "The Pleasures and Pains of Distinct Self-Construals: The Role of Interdependence in Regulatory Focus," Journal of Personality and Social Psychology, 78(6), 1122-134. doi:10.1037/ 0022-3514.78.6.1122

Matelesta, Carol Z. and Carroll E. Izard (1984), "The Facial Expression of Emotion:Young, Middle-Aged, and Older Adult Expressions," in Emotion in Adult Development, Carol Z. Matelesta and Carroll E. Izard, eds. Beverly Hills, CA: Sage, 253-73.

Mussweiler, Thomas, Katja Rüter, and Kai Epstude (2004), "The Man Who Wasn't There: Subliminal Social Comparison Standards Influence Self-Evaluation," Journal of Experimental Social Psychology, 40(5), 689-96. doi: 10.1016/j.jesp.2004.01.004

Polman, Evan and Rachel L. Ruttan (2012), "Effects of Anger, Guilt, and Envy on Moral Hypocrisy," Personality and Social Psychology Bulletin, 38(1), 129-39. doi: 10.1177/0146167211422365

Ratner, Rebecca K. and Barbara E. Kahn (2002), "The Impact of Private Versus Public Consumption on Variety-Seeking Behavior," 
Journal of Consumer Research, 29(2), 246-57. doi: 10.1086/341574

Savary, Jennifer, Kelly Goldsmith, and Ravi Dhar (2014), "Giving Against the Odds: When Highlighting Tempting Alternatives Increases Willingness to Donate," Journal of Marketing Research, 52(1), 27-38. doi: 10.1509/jmr.13.0244

Shah, James, Tory Higgins, and Ronald S. Friedman (1998), "Performance Incentives and Means: How Regulatory Focus Influences Goal Attainment," Journal of Personality and Social Psychology, 74(2), 285-93, doi: 10.1037/0022-3514.74.2.285

Tesser, Abraham, Murray Millar, and Janet Moore (1988), "Some Affective Consequences pf Social Comparison and Reflection Processes: The Pain and Pleasure of Being Close," Journal of Personality and Social Psychology, 54(1), 49-61. doi: 10.1037/0022-3514.54.1.49
Van de Ven, Niels, Marcel Zeelenberg, and Rik Pieters (2009), "Leveling Up and Down: The Experiences of Benign and Malicious Envy," Emotion, 9(3), 419-29. doi: 10. 1037/a0015669

Van de Ven, Niels, Marcel Zeelenberg, and Rik Pieters (2011a), "The Envy Premium in Product Evaluation," Journal of Consumer Research, 37(6), 984-98. doi: 10.1086/657239 Van de Ven, Niels, Marcel Zeelenberg, and Rik Pieters (2011b), "Why Envy Outperforms Admiration," Personality and Social Psychology Bulletin, 37(6), 784-95. doi: 10.1177/01461 6721140042

Weinstein, Netta and Richard M. Ryan (2010), "When Helping Helps: Autonomous Motivation for Prosocial Behavior and Its Influence on Well-Being for the Helper and Recipient," Journal of Personality and Social Psychology, 98(2), 222-44. doi: 10.1037/a0016984 


\section{〈Appendix A〉}

\section{Experiment 1: Emotion induction manipulation.}

a. Envy condition:

Please visualize and recall a prior experience when you envied another person (e.g., a popular girl/guy at school, a person who has something you want, someone who achieved your desirable goal etc.). Write about this specific time when you felt envious toward others. Please describe the situation in which you felt envious - what the specific situation was, why you were envious, what made you feel envious, how you felt, whether it was a negative or positive experience, etc.

\section{b. Neutral-emotion condition:}

Please visualize and recall your activities of yesterday. Write in detail about what you did throughout the course of the day. 


\section{〈Appendix B〉}

\section{Experiment 2: Emotion-Induction Manipulation}

a. Neutral-emotion condition (male version).

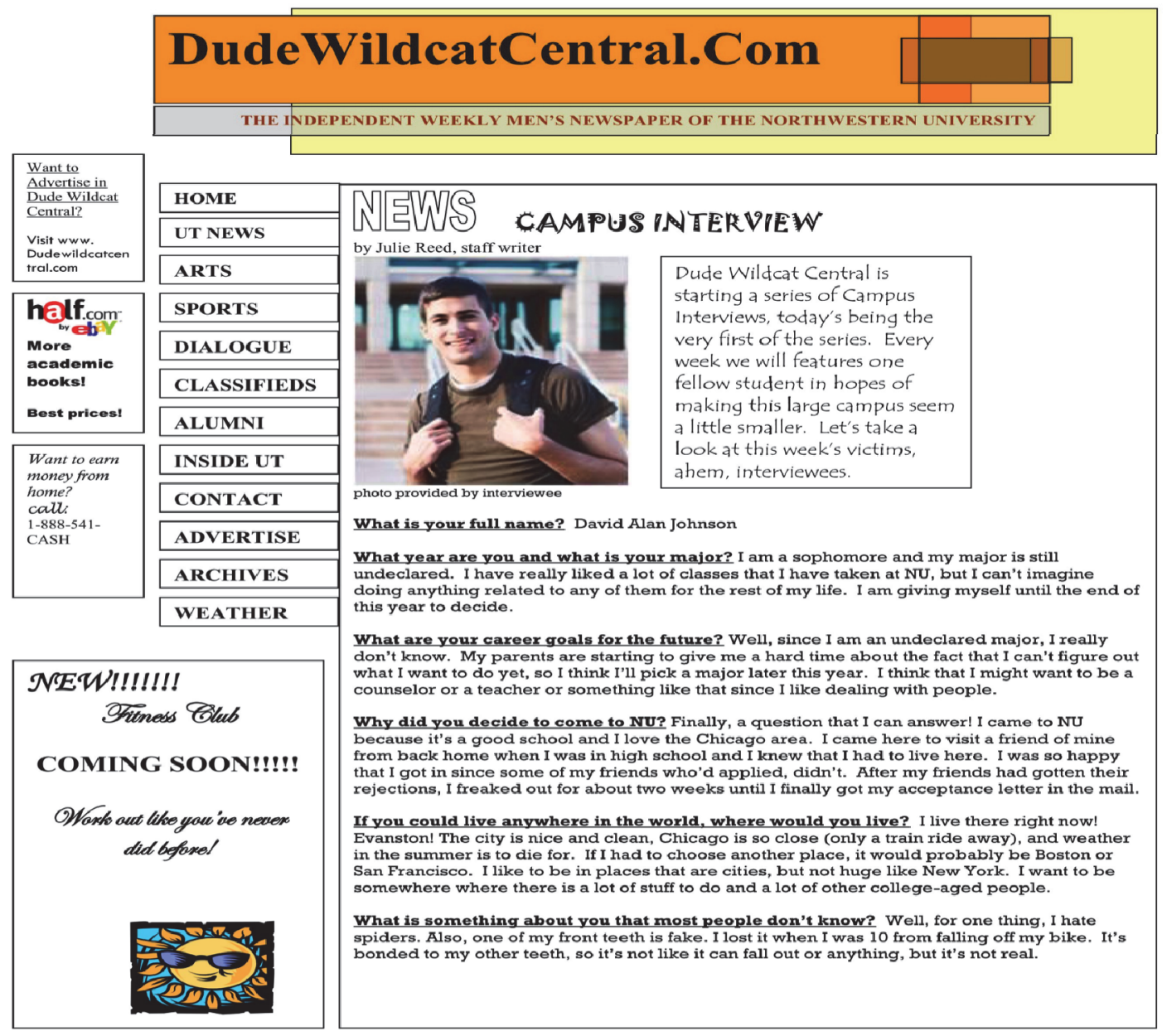


b. Neutral-emotion condition (female version).

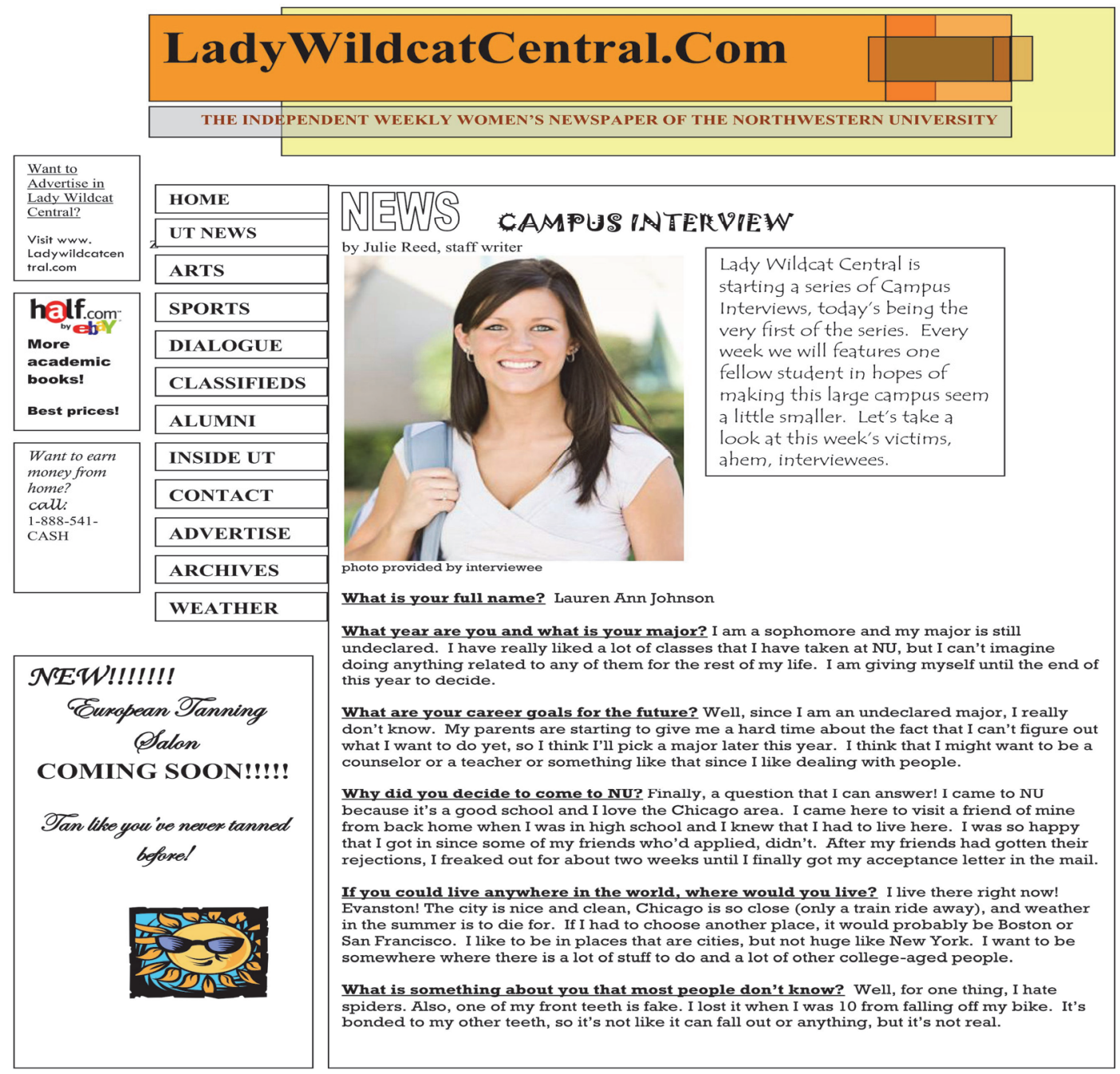

http://www.LadyWildcatCentral.com/section.php?section=news.html 


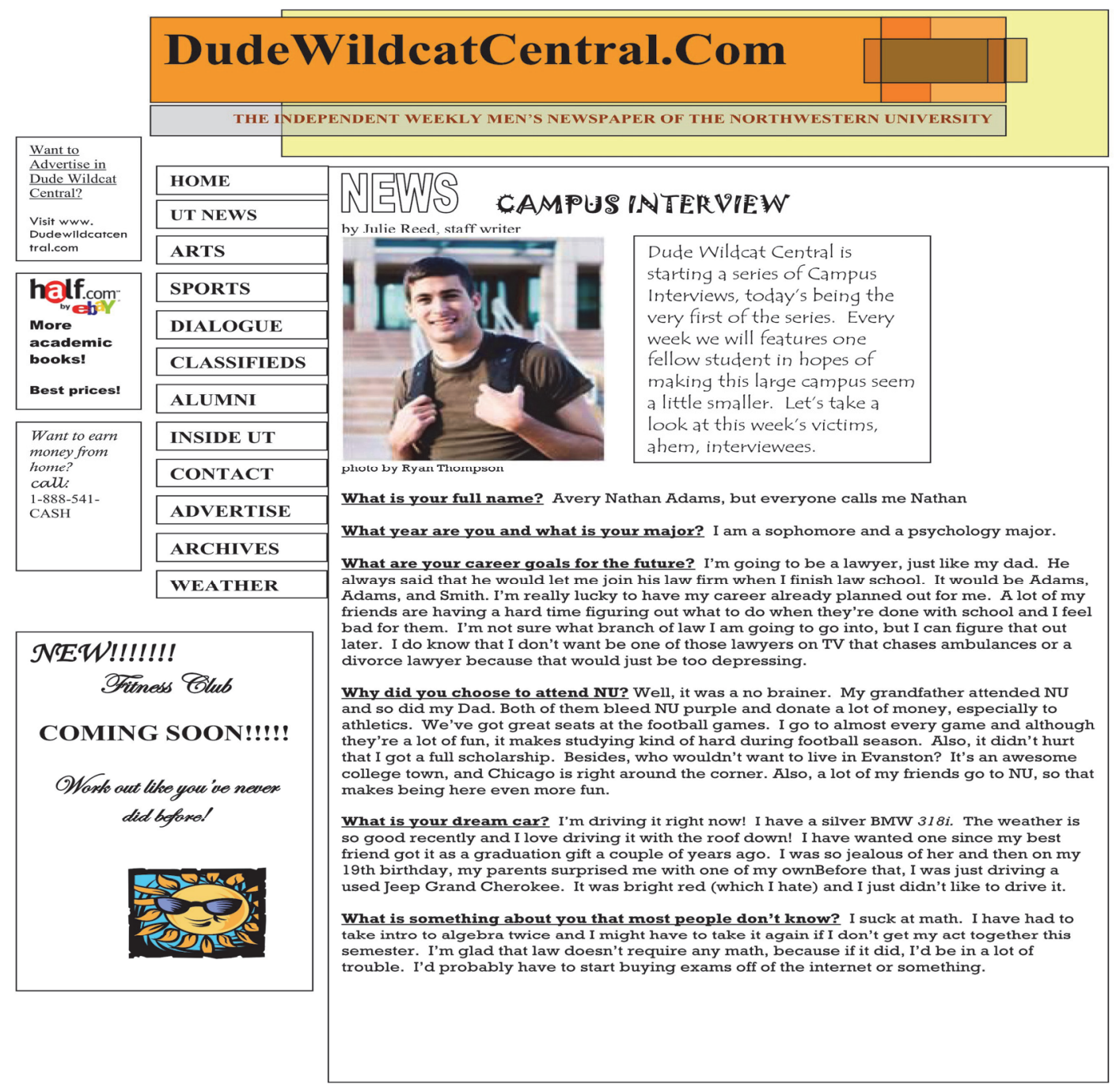

http://www.DudeWildcatCentral.com/section.php?section=news.html 


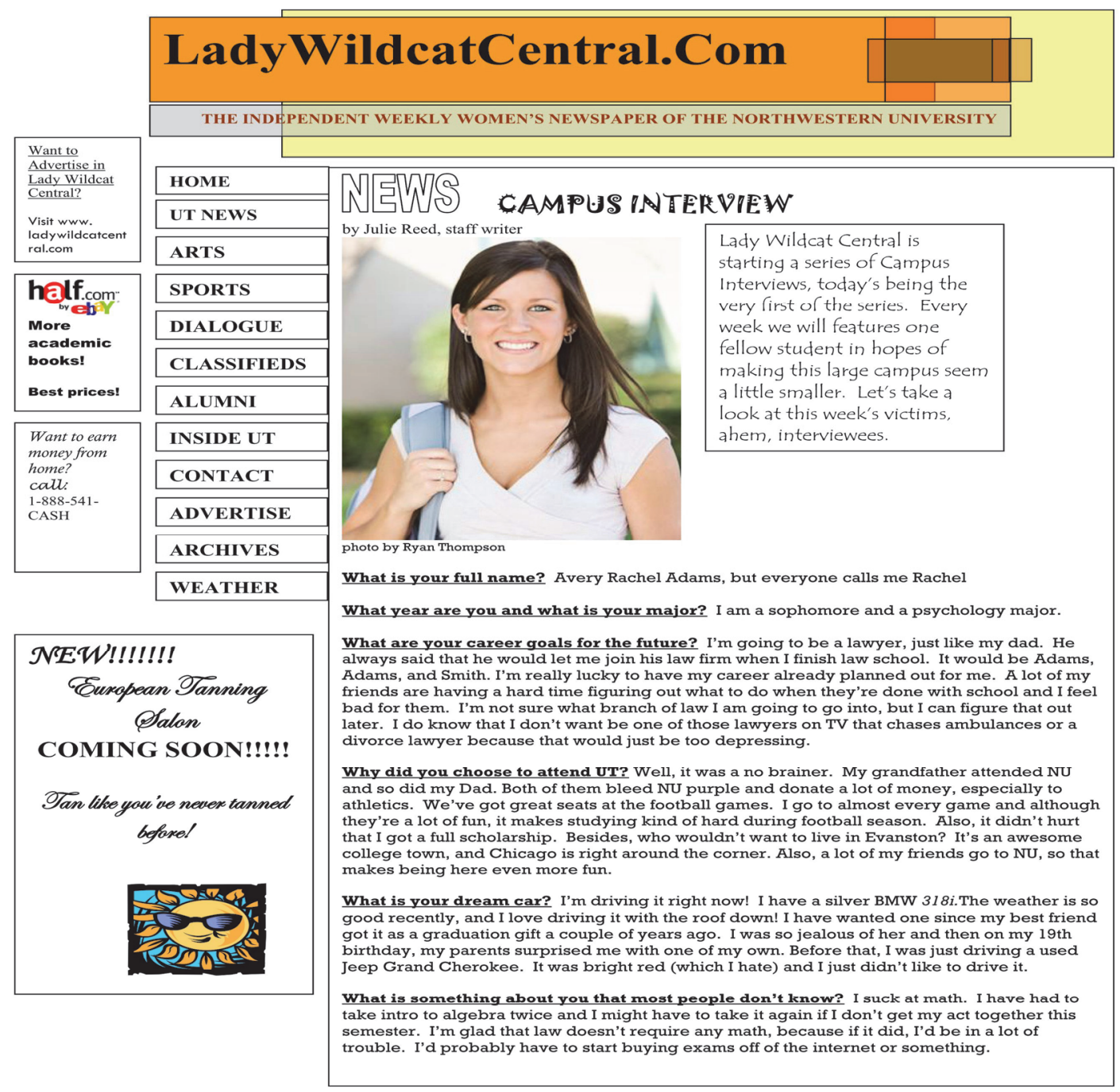

http://www.LadyWildcatCentral.com/section.php?section=news.html 